\title{
Os voos da Asa Branca: tradução e transculturação do baião brasileiro
}

\section{The flights of the White Wing: translation and transculturation of Brazilian baião.}

\author{
Marly D'Amaro Blasques Tooge*
}

Resumo: Este artigo discorre sobre a forma como a canção Asa Branca, um texto originado no sertão nordestino brasileiro migrou primeiramente para as áreas urbanas do país e depois para o cenário internacional, sendo apropriada por diferentes comunidades com um interesse comum: a questão do exílio. As diferentes versões da canção ao longo do tempo e em diferentes locais mostram que agendas pontuais e locais levaram à manipulação da letra original (e à adaptação do ritmo e do canto), sem, todavia, diminuir o impacto do tema universal que é o desterro.

Palavras-chave: Tradução; música; transculturação; representação; disseminação cultural.

Abstract: This article draws on how the song Asa Branca, a text originated in Brazilian backlands, migrated first to the urban areas of the country and then to the international scenario, being appropriated by different communities with a similar interest: the issue exile. The different rendering of the song along time and in different places show that timely and local agendas caused the manipulation of the original lyrics (and adaptation of rhythm and chanting), without, however reducing the importance of the impact of the universal theme that is losing one's home.

Keywords: Translation; music; transculturation; representation; cultural dissemination.

\footnotetext{
* Tradutora Pública e Intérprete Comercial do idioma inglês - prestando serviços ao Estado de São Paulo.
} 
TOoGE, M. D’A. B. - Os voos da Asa Branca: tradução e transculturação do baião brasileiro

Transpor fronteiras, transferir cultura, traduzir. Contar e cantar ao estrangeiro os enredos do Brasil. Essas não são atividades tão estranhas aos Estudos da Tradução. Afinal, é justamente dessa transposição de elementos linguísticos e culturais que trata a área de Estudos da Tradução.

Neste artigo, falamos da tradução artística relacionada ao campo musical. Não, não falamos do samba, consagrado internacionalmente na voz de Carmen Miranda. Não é sobre ritmo divulgado no período da Segunda Guerra, como consequência da Política de Boa Vizinhança norte-americana que aqui discorreremos. Também não se trata do sucesso da Bossa Nova, impulsionada pela necessidade de se substituir o chá-chá-chá nos Estados Unidos após a Revolução Cubana. Estes são ritmos importantes, sim, pois juntos criaram a essência de uma identidade paradisíaca, tropical, e em grande medida, estereotipada do Brasil desde o início do século XX (TOOGE 2014). Todavia, escolhemos falar de algo menos óbvio. Trataremos do forró, ou mais exatamente do baião, derivado do forró, ritmo criado pelos músicos Luiz Gonzaga e Humberto Teixeira.

Mas o que é um "forró"? Uma festa nordestina, o ritmo tocado nas festas juninas ou um gênero musical? De certa forma, todas essas coisas. Até mesmo para a origem do termo forró não existe apenas uma versão. Duas são conhecidas e divulgadas pelo Brasil. 0 princípio das duas é o mesmo: o termo se originou nas festas dançantes regionais nordestinas. A primeira é a de que, havia presença da empresa Western of Brasil Railway Co. no Nordeste, em função da construção das ferrovias locais no início do século XX até a década de 1950, época de sua estatização. Os operários ingleses que ali trabalhavam tinham o hábito de organizar bailes nas noites de folga e, para indicar que tais bailes eram abertos ao público, colocavam placas com o aviso "for all", expressão que seria então transformada em "forró" pela população local. A outra versão, mais verossímil, é que "forró" seria a contração de "forrobodó", que era o nome dos bailes dançantes da região (CHIANCA 2006: 87). Por essa razão, "forró" tornou-se um termo "guarda-chuva", que passou a significar a 
Tooge, M. D’A. B. - Os voos da Asa Branca: tradução e transculturação do baião brasileiro

festa, abrigando "vários estilos dançantes e que têm em comum uma temática relacionada ao grupo social de onde procede esta música". Entre esses estilos estão o xote, de origem portuguesa, o baião, o coco, o rojão, a quadrilha e o xaxado. O toré indígena é também associado ao "rastapé" do "forró", em função de ser uma dança onde se "arrastam os pés". Como comenta Expedito Leandro Silva, "sendo for all ou forrobodó a origem do termo forró, ambas refletem um fundo sociológico comum, isto é, dizem respeito ao universo do merecido lazer após a jornada de trabalho" (SILVA 2003: 72).

Já a transformação do "forró" em "baião" teve sua origem atribuída ao músico Luiz Gonzaga, alguém cuja imagem no Brasil se tornou irrefutavelmente ligada a esses ritmos:

Filho do sanfoneiro Januário (tocador e consertador de sanfona, Luiz Gonzaga assimilou o manejo do instrumento e o ethos musical nordestino manifesto na toada triste e nas danças de umbigada remanescentes do antigo lundu. Quando chegou ao Rio, sentiu que seu toque de sanfona e seu ritmo marcado eram suficientes para animar festas, bailes e mesmo pequenos shows dançantes. Para a rádio, porém, era necessário encontrar uma forma de canção mais definida e estabilizada sem aquele caráter de improviso interminável das rodas de festa nordestina. Fundamental, portanto, seu encontro com o cearense Humberto Teixeira. Projetaram em conjunto a batida, a levada, a dimensão, a temática e o estilo do baião (TATIT 1996: 149).

Os ritmos da viola sertaneja, do acordeão tocado nas festas das zonas rurais, assim, chegaram ao território urbano pela voz de Luiz Gonzaga. Para Moraes, é nos "espaços intersticiais e de deslocamento do Sertão nordestino e do Sudeste do país que o repertório de Gonzaga será construído (...) na sua música o Nordeste aparece como interlocutor do Sudeste" (MORAES 2009: 2). Assim, o processo de invenção de uma "tradição de nordestinidade" presente na obra de Luiz Gonzaga "conta com imagens de ruralidade e oralidade lembradas do passado", tornadas presente pelo "filtro da memória num cenário de migração urbano (...)". 
TOoGE, M. D’A. B. - Os voos da Asa Branca: tradução e transculturação do baião brasileiro

Ocorre também que "a emigração de nordestinos para o Sudeste ampliava a demanda por 'coisas da terra'” (COSTA 2012, grifo do autor). Assim, a rádio seria o meio que Gonzaga utilizaria para atingir e conquistar o público de migrantes nordestinos e, dessa forma, atingir mais facilmente o sucesso.

Como a música do Nordeste era pouco difundida à época, "para uma maior repercussão artística nacional, o Nordeste precisava de um novo ritmo de expressão" (COSTA 2012: 138). Na verdade, o ritmo radiofônico da época exigia que as canções fossem mais “dançantes”. Diz Costa que “Gonzaga, junto do seu primeiro grande parceiro, Humberto Teixeira, fariam esse ritmo: o Baião (...)" e foi com o baião "que Luiz Gonzaga fez sua primeira entrada triunfal na história da música popular brasileira” (DREYFUL 1996: 110 apud COSTA 2012: 138).

Apesar da afirmação de Costa (de que Luiz Gonzaga e Humberto Teixeira tenham "inventado" o baião), a própria dupla admitia que o baião era muito antigo, tendo 3 a 4 séculos de existência. ${ }^{1} 0$ baião teria nascido de uma forma derivada do lundu tocada pelos violeiros da zona rural nordestina, chamado por eles, inicialmente, de "baiano". A corruptela "baião" viria em seguida (TINHORÃO 1974: 209-217).

Jonas Rodrigues de Moraes (2013) discorreu sobre a origem do baião e sua relação com os batuques, o lundu e mesmo a modinha. Moraes cita, entre outras coisas, a características dançantes, de improviso e a existência do desafio entre os cantores do baião no Nordeste brasileiro do século XIX, assim como suas similaridades com outros ritmos, como o tango brasileiro e o maxixe. 0 autor afirma que "o baião emergiu no movimento de reinvenção de tradição sob os efeitos da tradução cultural", tendo se movido "por terrenos fronteiriços, saindo do campo (...) para o território urbano" (pp. 9). Completa, ainda, o autor: "Luiz Gonzaga e Humberto Teixeira se tornaram agentes responsáveis pela tradução diaspórica do baião" (2013: 9).

Essa "tradução diaspórica" foi, de certa forma, confirmada pelos músicos nordestinos. "O que eu fiz com Luiz foi urbanizar, citadinizar, estilizar, dar características sulinas para aquelas coisas e àquele ritmo da viola

\footnotetext{
${ }^{1}$ A origem do baião foi estudada por Câmara Cascudo, entre outros.
} 
Tooge, M. D’A. B. - Os voos da Asa Branca: tradução e transculturação do baião brasileiro

sertaneja", afirmou Humberto Teixeira em um especial da Rede Globo, reexibido pela Globo News em 2012. ${ }^{2}$ A dupla que criou a canção também chamada "Baião" trouxe a história e a cultura sertaneja, ou nas palavras do próprio Humberto Teixeira, “a história dos nossos irmãos do norte, para que nossos irmãos do sul conhecessem". ${ }^{3}$

Foi, dessa forma, da parceria entre o cantor e compositor de forró Luiz Gonzaga com o advogado Humberto Teixeira, iniciada em 1945, que surgiu, dois anos mais tarde, a canção que se tornou o hino dos retirantes nordestinos: Asa Branca. Nela, o compositor Humberto Teixeira descreve o problema da seca e do migrante nordestino, reproduz o socioleto local e inclui desvios da norma culta, para representar a fala popular.

Mas é a descrição da dor do retirante, sua angústia, o que, em nossa opinião, mais marca a letra da canção:

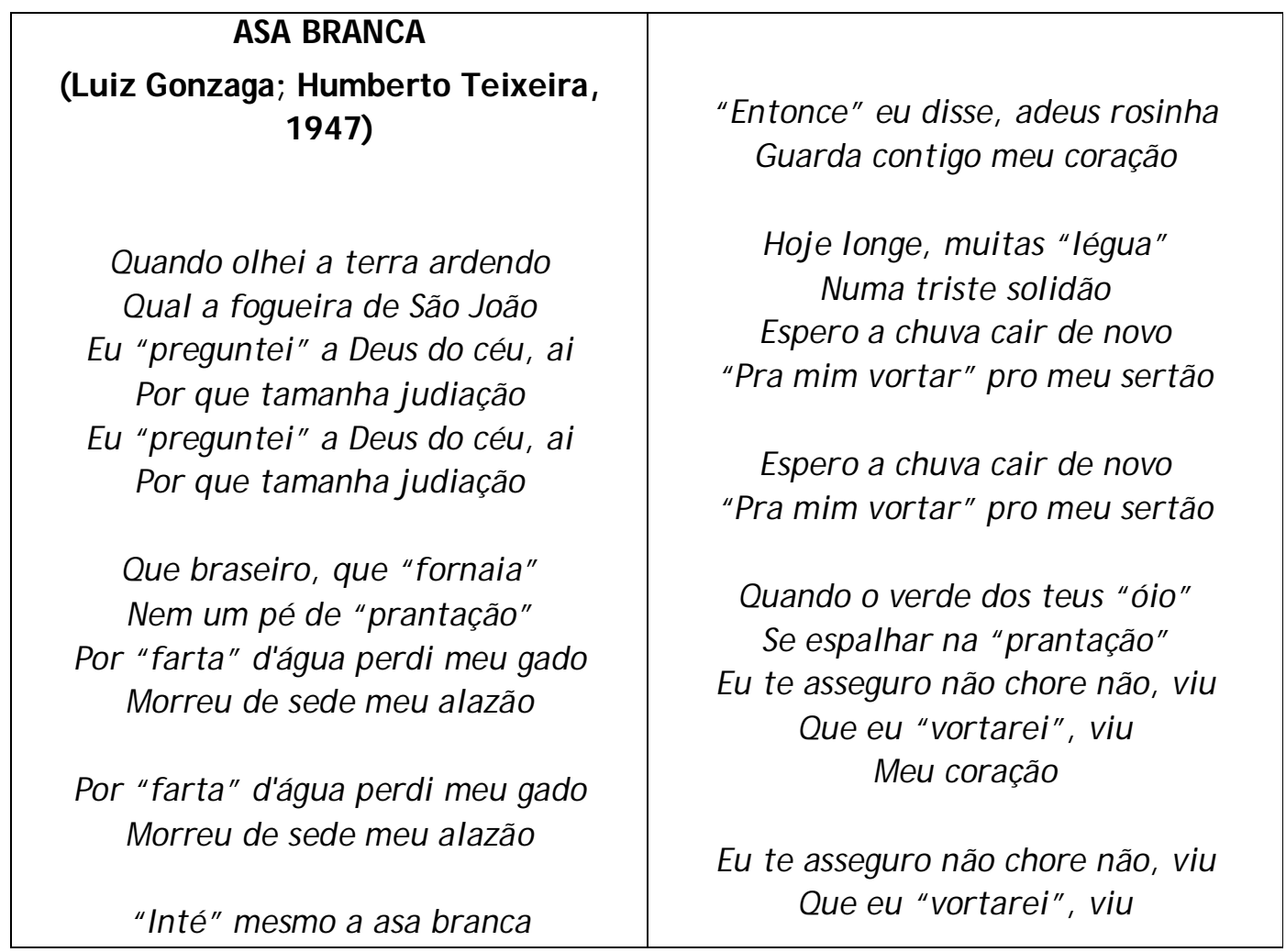

${ }^{2}$ QUEM inventou o Baião? - Luiz Gonzaga e Humberto Teixeira. 2012. 1 vídeo. Programa Arquivo N, especial exibido pela Globo News. Disponível em: www.youtube.com/watch?v=W_BEigHAzpw. Acesso em: 5 fev. 2014.

${ }^{3}$ Ibidem. 
TOoGE, M. D’A. B. - Os voos da Asa Branca: tradução e transculturação do baião brasileiro

\begin{tabular}{|c|c|}
\hline $\begin{array}{c}\text { Bateu asas do sertão } \\
\text { “Entonce" eu disse, adeus rosinha } \\
\text { Guarda contigo meu coração }\end{array}$ & Meu coração \\
\hline
\end{tabular}

A canção mostra a força da natureza, da seca, que expulsa o sertanejo, que o desterra. Há também o uso do socioleto, carregando significados fortes de raízes sociais, do posicionamento do interlocutor e de identidade. Usar o socioleto é localizar o falante hierarquicamente, enquanto se marca na letra a busca de soluções concretas para a dor do cotidiano.

Mas o mais intrigante é que existe uma metáfora muito maior na canção de Humberto Teixeira: a "Asa Branca” é o próprio retirante, o migrante obrigado ao exílio em função das dificuldades naturais, sociais ou econômicas. Até mesmo um estrangeiro que perdesse suas propriedades em função de uma guerra poderia se identificar com a letra da canção. Isso sem levar em conta os efeitos melódicos criados por Luiz Gonzaga. Com a canção podem se identificar exilados, migrantes, expatriados de todo o mundo.

Tudo isso permite que existam inúmeras apropriações da canção. Luiz Gonzaga e Humberto Teixeira não eram compositores envolvidos em defesas políticas ou grupos ideológicos. Mas por ter feições de "denúncia social”, sua criação foi transformada em “canção de protesto” por Geraldo Vandré, em seu LP Hora de lutar, em 1965.

Asa Branca ganhou sua primeira versão em inglês em 1970, criada pelo roqueiro Raul Seixas, “o filho de Luiz Gonzaga com Elvis Presley”, conforme o próprio cantor gostava de brincar. ${ }^{4}$ Foi, ironicamente, a mais "americanizada" de todas as que surgiriam. O ritmo era o mesmo da tradicional country music norte-americana, com o uso da guitarra elétrica substituindo a sanfona. Qualquer um que ouvisse a canção pela primeira vez, a reconheceria como música estrangeira. A canção fazia até mesmo a correspondência entre “alazão” e o “appaloosa”, uma raça de cavalos também tipicamente norteamericana. Raul Seixas insere a palavra "me" na estrofe "If I deserve me this

\footnotetext{
${ }^{4}$ Ver documentário 0 homem que engarraf ava nuvens (2008).
} 
Tooge, M. D’A. B. - Os voos da Asa Branca: tradução e transculturação do baião brasileiro

kind of pain", possivelmente na tentativa de simular ou imitar o caráter oral canção regional que reproduz.

\begin{tabular}{|} 
WHITE WING \\
(Versão de Raul Seixas, 1970) \\
When I stare the ground of my land \\
Burning loose as dancing flames \\
I asked the man up in the heavens \\
If I deserve me this kind of pain \\
Everywhere the ground is so dry \\
No trees, no green, just red \\
I lost my cattle, my appal oosa \\
For lack of water some took away \\
Even the white winged bird flew away \\
Flew away from my land sight \\
It was when I said goodbye Sweet Rosie \\
Keep in to your heart this heart of mine \\
Many thousands miles away, now \\
Feeling lonely, lost and blue \\
I keep on waiting rain falls again there \\
So I'II be back dear, (I'II) come home again \\
I keep on waiting rain falls again there \\
So I'll can move back to home again \\
When the glow green of your eyes \\
Flows again all over land \\
I can assure you, so don't \\
You cry, no 'cause I'II be back, see \\
To you again!!
\end{tabular}

Em 1975, o cantor grego Demis Roussos gravou outra versão da canção em inglês, também chamada White Wings. O ritmo agora era muito mais melódico, orquestrado do que o original, combinando com o romantismo que foi dado à letra da canção, que em nada corresponde ao original, nem semanticamente, nem formalmente. O que existe é o elogio à natureza exuberante, enquanto nenhuma das outras questões sociais mencionadas na canção original são trazidas por Roussos.

Os exemplos se tornam mais relevantes quando comparados ao próximo: mais recentemente, em 2009, a canção foi gravada por um grupo brasileiro que 
Tooge, M. D’A. B. - Os voos da Asa Branca: tradução e transculturação do baião brasileiro trabalha em Nova York, chamado "Forró in the Dark" - cujo nome é a versão em inglês de Forró no escuro -, canção de Luiz Gonzaga de 1958. O título não deixa de ser bilíngue (ou híbrido), uma vez que não há tradução para o termo "Forró".

David Byrne, produtor da banda, é também o cantor da música. É importante lembrar a grande atração de Byrne pelos membros do movimento Tropicália (como Tom Zé, Caetano Veloso e Gilberto Gil) que trouxeram de volta a ideia oswaldiana de "devorar" a influência estrangeira sem abolir o elemento importante da cultura brasileira. Na verdade, o que essa versão da canção faz é o inverso: inserir a cultura e a língua brasileiras no ambiente externo, e de alguma forma "inverter" as hierarquias. 
TooGE, M. D’A. B. - Os voos da Asa Branca: tradução e transculturação do baião brasileiro

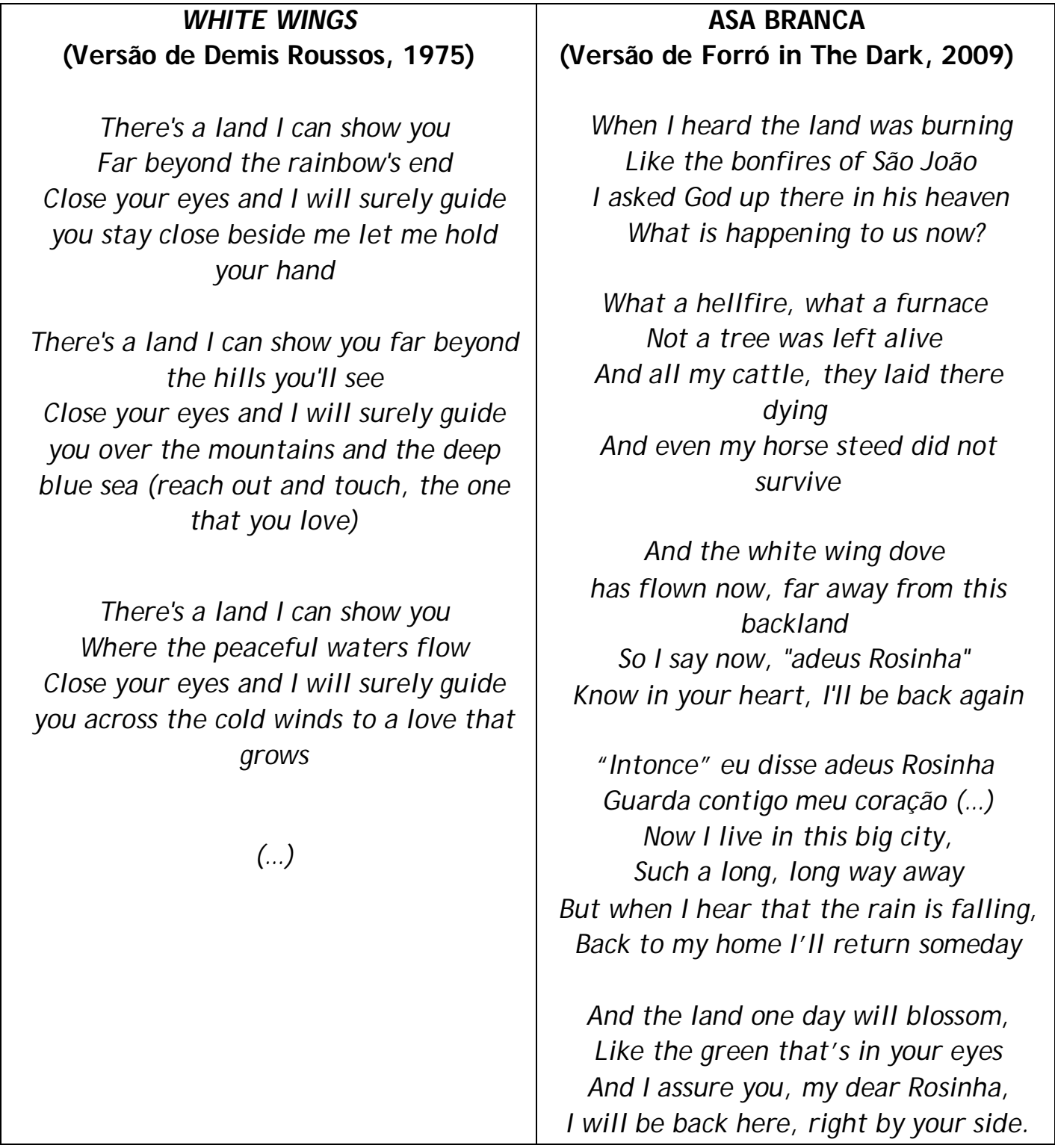

Muitos elementos da cultura brasileira são mantidos na versão em inglês de Byrne. "São João", uma festa típica do sertão, que se espalhou por todo o Brasil, é descrita na canção em inglês através de suas fogueiras típicas. 0 nome "Rosinha" foi mantido como no original, de forma a quebrar o ritmo das palavras inglesas, uma estratégia "estrangeirizadora". 0 estribilho em português força aqueles que acompanham a canção a deslocar-se de um código a outro (do inglês para o português). Assim, a letra da canção do Forró in the 
TOoGE, M. D’A. B. - Os voos da Asa Branca: tradução e transculturação do baião brasileiro

Dark permite que os conteúdos culturais do original sejam mais visíveis, certamente muito mais do que nas versões de Raul Seixas ou Demis Roussos.

Em 2010, o cantor de forró Roberto Trevisan, após um contato em um show em Manhattan com Billy Paul, que o viu cantar Asa Branca e se interessou pela canção, decidiu fazer mais uma versão da canção para o inglês. ${ }^{5}$ Os dois cantaram a versão ao redor do Brasil e o vídeo pode ser acessado pela Internet. A parceria recorre novamente à estratégia de colaboração entre um músico renomado em um país anglo-saxão e um bem menos famoso no Brasil.

\begin{tabular}{|c|c|}
\hline $\begin{array}{c}\text { WHITE WING } \\
\text { (Versão em inglês de Roberto } \\
\text { Trevisan, 2010) }\end{array}$ & [Os dois cantores elogiam Luiz Gonzaga] \\
\hline $\begin{array}{l}\text { When I heard my land cry } \\
\text { Like a fire in the sky } \\
\text { I asked God to quide our hands }\end{array}$ & $\begin{array}{l}\text { Many thousands miles away } \\
\text { Now feeling lonely, lost and blue } \\
\text { Rain fall again there }\end{array}$ \\
\hline $\begin{array}{l}\text { And give us hope, to bless this land } \\
\text { I asked God to guide our hands }\end{array}$ & So I'll be back to home again \\
\hline And give us hope, to bless this land & $\begin{array}{c}\text { When the glow green } \\
\text { Of your eyes }\end{array}$ \\
\hline $\begin{array}{l}\text { Everywhere the ground is dry } \\
\text { There is no trees, no green, just filth }\end{array}$ & $\begin{array}{l}\text { Falls again all over the land } \\
\qquad \text { I can assure you }\end{array}$ \\
\hline I lost my cattle, my appaloosa & So don't you cry, no \\
\hline For lack of water, some took away & $\begin{array}{c}\text { 'Cause I'll be back to } \\
\text { See you again }\end{array}$ \\
\hline $\begin{array}{l}\text { Even the White wing birds flew away } \\
\text { Flew away from my land side } \\
\text { It's when I say: Good bye sweet Rosie } \\
\text { Keep in your heart, this heart of mine. }\end{array}$ & $\begin{array}{c}\text { Cause l'Il be back to } \\
\text { See you again }\end{array}$ \\
\hline
\end{tabular}

A versão de Trevisan se inicia de forma bem mais religiosa do que a letra original de Luiz Gonzaga, já que a expressão "land cry", referindo-se ao "clamor da terra", é fórmula muito encontrada nos textos bíblicos, como no

\footnotetext{
${ }^{5} \mathrm{O}$ fato foi anunciado também no website da comunidade brasileira de Connecticut; New York; New Jersey, e está disponível em: www.comunidadenews.com/cultura/asa-branca-de-luizgonzaga-ganha-versao-em-ingles-cantada-por-roberto-trevisan-e-billy-paul-6174, acesso em: 10 fev. 2014.
} 
Tooge, M. D’A. B. - Os voos da Asa Branca: tradução e transculturação do baião brasileiro

livro de Jeremias (12: 4$)^{6}$ ou no livro de Jó $(31: 38) .{ }^{7}$ Ao mesmo tempo, Trevisan inseriu um pedido de benção a Deus além de que Ele seja um guia, inexistente no original.

$\mathrm{Na}$ segunda estrofe, entretanto, Trevisan acaba por copiar duas linhas da versão já existente de Raul Seixas: “I lost my cattle, my appaloosa”. Além disso, as frases são muito longas e, para serem inseridas no ritmo da canção em inglês, acabam tendo que ser cantadas apressadamente, como pode ser verificado no vídeo da gravação, mostrando a dificuldade na reelaboração da canção. ${ }^{8}$

A versão de Trevisan se torna mais "fiel" aos sentidos do texto original no restante da canção, embora os sentidos do socioleto retratados no termo “prantação” também desapareçam na versão em inglês.

Parece, porém, que através de sua versão, Trevisan tenha desejado pôr em prática a ideia, por ele mesmo manifesta", de "cantar nossa cultura em inglês". Todavia, na letra desse versionista, existe um subtexto, ou até a intertextualidade com os textos da Bíblia cristã. Trevisan anunciou no artigo citado que a ideia era levar a música de Luiz Gonzaga, o forró, ao mundo inteiro. Como veremos logo adiante, o Rei do Baião conseguiu essa vitória sem sua ajuda.

Cabe, contudo, falarmos de uma última versão de Asa Branca, em um caso que nos despertou muito interesse. Ela faz parte da história de Marcos

\footnotetext{
6 "How long must the land cry out in mourning, the grasses of the field wither and bake in the sun?" - Jeremiah (12: 4). In: BíBLIA. Inglês. The Voice Bible. Disponível em: www. biblegateway.com/passage/?search=Jeremiah+12\%3A4\&version=VOICE. Acesso em: 18 jan. 2014.

7 "If my land cry against me, or that the furrows likewise thereof complain" - Job (31: 38). In: BíBLIA. King J ames Bible. Disponível em: www.kingjamesbibleonline.org/Job-31-38/. Acesso em: 25 fev. 2014.

8 WHITE Wing - (AKA Asa Branca) Roberto Trevisan and Billy Paul. [s.d.]. 1 vídeo. Disponível em: www.vejatv.com/video-15505. White-Wing---AKA-Asa-Branca-Roberto-Trevisan-and-BillyPaul-.html. Acesso em: 10 fev. 2014.

9 Ver artigo '“ASA BRANCA' de Luiz Gonzaga ganha versão em inglês, cantada por Roberto Trevisan e Billy Paul". In: Comunidade News - O Jornal da Comunidade Brasileira, Connecticut; New York; New Jersey, 26 May 2010. Disponível em: www.comunidadenews.com/cultura/asabranca-de-luiz-gonzaga-ganha-versao-em-ingles-cantada-por-roberto-trevisan-e-billy-paul6174. Acesso em: 10 fev. 2014.
} 
TOoGE, M. D’A. B. - Os voos da Asa Branca: tradução e transculturação do baião brasileiro

Lombello. Professor da Universidade Normal de Quanzhou desde 2003, Lombello sentia o interesse dos alunos da universidade no Brasil e sua cultura.

Também músico e compositor, Lombello relata sempre ter usado a música como recurso para o ensino de línguas. Em 2012, ele e seu grupo lançaram o Projeto Amizade China-Brasil, gravando material "transcultural", como ele mesmo afirma. Ou seja, suas versões em língua inglesa eram utilizadas para ensinar o idioma inglês, passando a cultura brasileira. Um caso, sem dúvida, muitíssimo interessante no que se refere à transculturação, ainda mais, com a divulgação que Marcos Lombello tem conseguido de seu trabalho, através da Intenet, sem nenhum incentivo governamental.

A "Asa Branca" em chinês tem história interessante: primeiro fiz a versão em inglês para os meus alunos cantarem na aula, do mesmo jeito que eu fiz a versão em inglês de "Riacho do Navio" do Luís Gonzaga. Meses depois pedi à minha aluna Rebecca Lin para me ajudar a fazer a letra em chinês, preservando sempre que possível 0 sentido original de cada frase. Trabalhamos junto, estrofe por estrofe, e em uma tarde - cerca de quatro horas de trabalho - nasceu Bai Chibang. (LOMBELLO, em entrevista que nos foi concedida em 2013 - Ver Anexo I).

O professor versionista afirma que "a verdade, o sentimento, o espírito de brasilidade, mas acima de tudo, a transcendência do elemento humano, que supera todas as barreiras culturais quando se expressa através da arte, trazendo alegria por todos os lados" é a maior característica de nossa cultura que deve ser passada ao estrangeiro. A escolha de "Asa Branca" foi, segundo o músico, por gostar da canção e achar que ela representa parte da cultura do nordeste, seu lugar de origem.

Lombello relatou, ainda, que "além das dificuldades naturais de criar versões que mantenham o sentido geral, tenham beleza poética e caibam na melodia" ele precisava lidar com as diferenças culturais que podiam prejudicar o entendimento dos conceitos das canções. "Por exemplo, na China há quem perceba 'Asa Branca' como música religiosa, por causa da frase 'perguntei a Deus do céu..."”. É interessante que essa preocupação nem sequer chegou à 
Tooge, M. D’A. B. - Os voos da Asa Branca: tradução e transculturação do baião brasileiro

mente de Roberto Trevisan, que criou uma versão abundante em termos religiosos.

Apesar do pouco interesse das comunidades internacionais pela música de outros países, Lombello testemunhou que seu trabalho é recebido, na China, “com surpresa e entusiasmo", além de "uma curiosidade de valor meramente exótico", que obviamente não deixaria de existir. Todavia, Lombello reclama que "sem investimento [governamental], a cultura brasileira NUNCA (grifo do autor) vai penetrar a couraça cultural tradicionalista chinesa”, o que gera mais um desperdício do "potencial do maior mercado cultural do mundo".

Vejamos o trabalho de Lombello com “Asa Branca”:

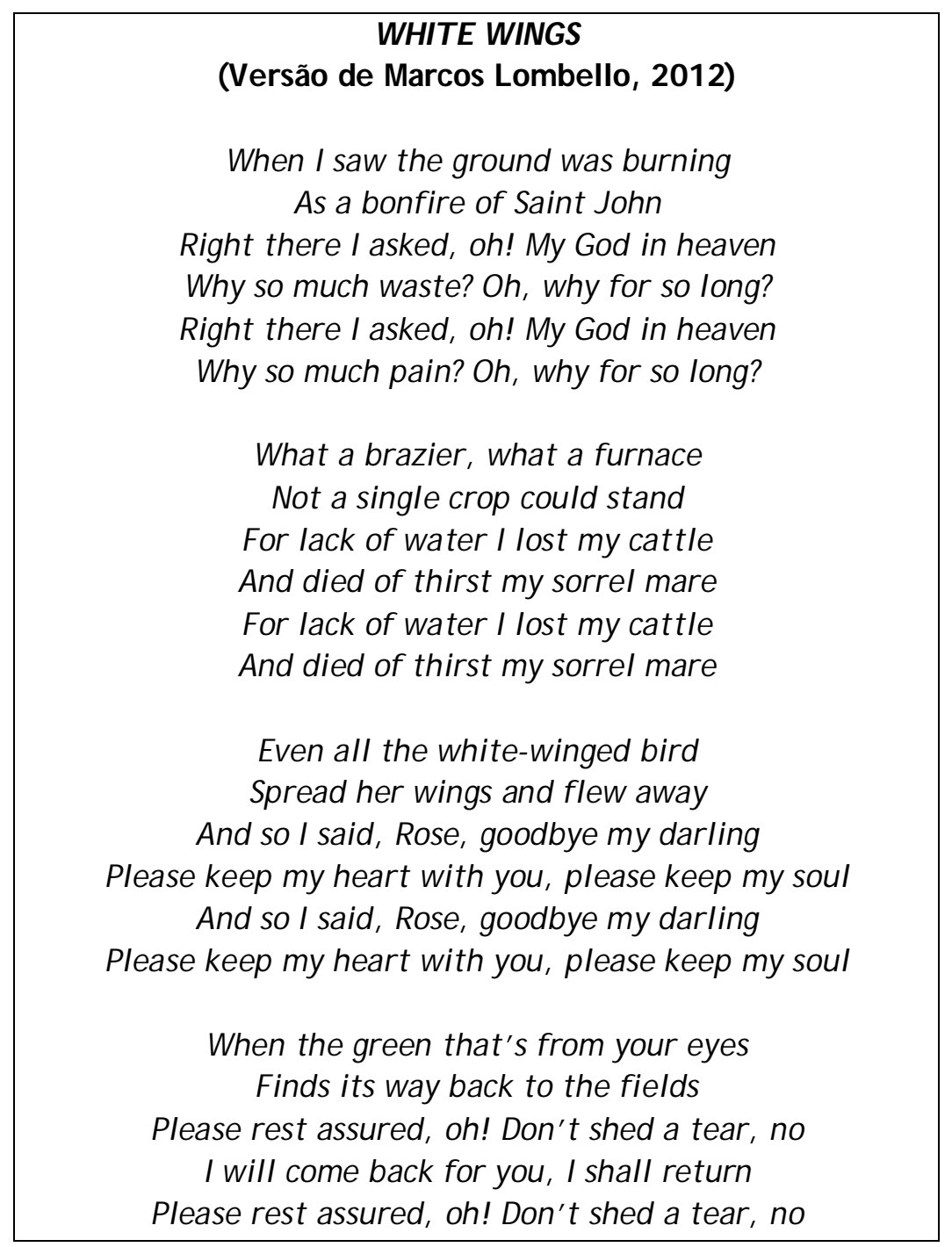

TradTerm, São Paulo, v. 25, Agosto/2015, pp. 153-168 www.usp.br/tradterm 
TOoGE, M. D’A. B. - Os voos da Asa Branca: tradução e transculturação do baião brasileiro

\begin{tabular}{|}
\hline I will come back for you, I shall return \\
Far away, so many miles \\
In this sad and Ionely life \\
I wish the rain will fall once again \\
So I can be there on my motherland \\
I wish the rain will fall once again \\
So I can return to my motherland
\end{tabular}

$\mathrm{Na}$ versão de Marcos Lombello, verificamos o cuidado com as rimas, revelado em sua preservação, assim como a manutenção de todos os elementos semânticos do original. Foi a versão que mais se aproximou da canção original, sendo a única a buscar uma correspondência para "Por que tamanha judiação", vertida como "Why so much waste? Oh, why for so long?”. Na canção original, “judiação” aparece com o sentido de "pena”, “lástima”, o que surge na correspondência como "waste". Já o termo "tamanha", com sentido de "grande", “muita”, tem sua correspondência obtida através de uma compensação com a ideia de tempo prolongado de “for so long”. Lombello também parece apresentar a melhor correspondência para "Quando o verde dos teus óios se espaiá na prantação", com os versos "When the green that's from your eyes finds its way back to the fields", mostrando uma melhor maestria dos idiomas e uma maior capacidade de inserção da letra vertida no ritmo da canção.

Apesar de não utilizar estratégias de bilinguismo (code-switch), a versão de Lombello se mostrou, em nossa opinião, bastante eficiente, e cumpriu o que Lombello disse em sua entrevista, ou seja, criou uma versão que manteve o sentido geral do original, com beleza poética, que coube na melodia, lidando ainda com as diferenças culturais.

Vimos, assim, que a Asa Branca voou de diferentes formas por territórios que compreendem o idioma anglo-saxão. Seria um grande erro, entretanto, imaginar que a peregrinação do forró se restringiu a tais territórios. É verdade 
Tooge, M. D’A. B. - Os voos da Asa Branca: tradução e transculturação do baião brasileiro

que os Beatles chegaram a usar "Asa Branca” de Luiz Gonzaga em seus ensaios ${ }^{10}$ e inseriram um pouco do ritmo na canção "The inner light", mas o baião também já havia migrado para o continente europeu no início da década de 1950, quando o ritmo foi inserido no filme italiano Anna (1951). O drama dirigido pelo diretor Alberto Larruada trazia a cantora Silvana Mangano no papel de uma cantora sensual que trabalhava em um clube noturno, e que, envolvida em um caso passional e de assassinato, decidia tornar-se freira. Enquanto trabalhava no clube, a protagonista cantava, em idioma espanhol, o baião El negro zumbon ${ }^{11}$, adaptado ao gosto europeu.

O que se viu foi o sucesso de uma canção cheia de "misturas": ritmo brasileiro (adaptado, já que não é exatamente um “rastapé” nordestino), cantado em espanhol por uma italiana.

Asa Branca foi gravada ainda em japonês ${ }^{12}$, coreano ${ }^{13}$, chinês ${ }^{14}$, turco ${ }^{15}$, na língua pulaar do Senegal ${ }^{16}$, e até mesmo em um formato versão próprio de Portugal ${ }^{17}$. Em todas as versões existiram adaptações ao ritmo local, incluindo o fado português. O caráter universal do tema da migração, todavia, parece ter sido mantido em quase todas.

Asa Branca é um excelente exemplo de transferência cultural do meio rural brasileiro (que também já recebia elementos culturais provenientes dos continentes africano, europeu ou local, de origem indígena) para o meio

10 Ver documentário do Museu Luiz Gonzaga Os Beatles tocaram Asa Branca?, também apresentado no programa "Matéria" da TV Itararé/ Cultura, de Campina Grande (PB), em 2 ago. 2011).

11 Vídeo disponível em: www.youtube.com/watch?v=j-HNZLg6ntl. Acesso em: 10 fev. 2014.

12 Vídeo disponível em: www.youtube.com/watch?v=1eEnVsQL4lY. Acesso em: 10 fev. 2014.

13 Vídeo disponível em:

www.youtube.com/watch?feature=player_embedded\&v=Eq8a6RVhrZ8\#!. Acesso em: 10 fev. 2014.

14 Vídeo disponível em: www.youtube.com/watch?v=xkaqxmfA_L4. Acesso em: 10 fev. 2014. Ver também entrevista com Marcos Lombello no ANEXO I.

15 Vídeo disponível em: www.youtube.com/watch?v=eo6hwhlehEc. Acesso em: 10 fev. 2014.

16 Vídeo disponível em: www.youtube.com/watch?v=XxleNT1lA-s. Acesso em: 10 fev. 2014.

17 Há uma versão portuguesa em ritmo de fado, de Isabel Silvestre. Vídeo disponível em: www.youtube.com/watch?v=fi8FhHo9ha8. Acesso em: 10 abr. 2014.

TradTerm, São Paulo, v. 25, Agosto/2015, pp. 153-168

www.usp.br/tradterm

http://www.revistas.usp.br/tradterm/index 
TOoGE, M. D’A. B. - Os voos da Asa Branca: tradução e transculturação do baião brasileiro

urbano, e então do ambiente nacional para o internacional. Notemos que o ritmo que se originou na África e na Europa, para lá retornou, modificado, deglutido, "antropofagicamente" recriado. E o mais interessante foi ele não ter precisado tanto de incentivos governamentais, dos impulsos de base ideológica, como foi o que ocorreu com o samba durante a política de Boa Vizinhança e com a Bossa Nova durante o período da Aliança para o Progresso.

Tais exemplos de transferência cultural são de grande valia para a compreensão dos valores que permeiam a tradução artística no mundo contemporâneo, e mostram que os traumas históricos de uma determinada população podem ser apropriados por outra como forma de expurgar as dores causadas pelas questões históricas locais. Tal fenômeno é importante para o estudo da formação de imaginários sobre comunidades e nações, e é um rico filão a ser explorado pelos Estudos da Tradução.

\section{Referências bibliográficas}

CHIANCA, L. A festa do interior: São João, migração e nostalgia em Natal no século XX. Natal, RN: Editora da UFRN, 2006.

COSTA, J. H. Luiz Gonzaga: entre o mito da pureza e a indústria cultural. Revista Espaço Acadêmico, Universidade Estadual de Maringá, n. 130, mar. 2012.

MORAES, J. R. de. A música de Luiz Gonzaga no território da "invenção das tradições”. In: Simpósio Nacional de História - NPUH, 2009, Fortaleza.

SILVA, E. L. Forró no asfalto: mercado e identidade sociocultural. São Paulo: Annablume, 2003.

TATIT, L. O cancionista: composição de canções no Brasil. São Paulo: EDUSP, 1996.

TOOGE, M. Harmonia e tom: o poder brando da música popular brasileira e as representações identitárias do Brasil no mundo. Tese de doutorado. FFLCH USP. 2014

Recebido em: 26 fev. 2015

Aprovado em: 7 ago. 2015

TradTerm, São Paulo, v. 25, Agosto/2015, pp. 153-168

www.usp.br/tradterm

http://www.revistas.usp.br/tradterm/index 